\title{
Paradox of Choice in Alliance Formation: A Network Embeddedness Approach
}

\author{
Jungwon $\operatorname{Min}^{1}$ \\ ${ }^{1}$ Faculty of Economics, Kyushu University, Fukuoka, Japan \\ Correspondence: Jungwon Min, Faculty of Economics, Kyushu University, Hakozaki 6-19-1 Higashi-ku, \\ Fukuoka 812-8581, Japan. Tel: 81-92-642-2476. E-mail: jwmin@econ.kyushu-u.ac.jp
}

Received: February 2, 2015

Accepted: February 20, 2015

Online Published: March 25, 2015

doi:10.5539/ibr.v8n4p155

URL: http://dx.doi.org/10.5539/ibr.v8n4p155

\begin{abstract}
Prior research on network embeddedness suggests that relational embeddedness (i.e., the duration of previous alliances between two firms) and structural embeddedness (i.e., the number of partners common to both firms) facilitate alliance formation between firms. This study examines the opposite case-namely, the inhibition of alliance formation by relational and structural embeddedness. In this study, by considering these two types of embeddedness as drivers of partner choice sets, I propose that a choice set larger than a certain threshold size with sufficiently low variation in terms of the embeddedness of their options (i.e., relationally or structurally embedded potential partners) enables firms to recognize multiple options within the choice set. I also suggest that this in turn increases firms' uncertainty about these options' resources and reliability and inhibits the formation of alliances with them. These predictions are supported by empirical tests of code-share alliance data in the global airline industry from 1994 to 2006.
\end{abstract}

Keywords: alliance, multi-option recognizability, partner choice set, relational embeddedness, structural embeddedness

\section{Introduction}

Scholars have long been interested in how firms can form alliances with a low degree of uncertainty. A network embeddedness approach suggests two types of such alliance: those with prior partners (i.e., relationally embedded alliances) and those with firms to which the firm is indirectly connected through current common partners (i.e., structurally embedded alliances). By selecting relationally or structurally embedded others as alliance partners, firms can reduce uncertainty regarding the capability and reliability of potential partners. This is because the prior alliance experience and common partners provide the firms with easy access to information about potential partners and give them some control over the partners' opportunistic behaviors through emotional intimacy and reputational referrals (Shipilov, Rowley, \& Aharonson, 2006; Uzzi, 1996). Accordingly, several prior studies have found that two firms that have prior partnerships or many common partners are likely to form a new alliance (Gulati, 1995; Uzzi, 1996) and that such alliances tend to produce strong gains (Capaldo, 2007; McFadyen, Semadeni, \& Cannella, 2009; Rowley, Behrens, \& Krackhardt, 2000).

Regardless of this comprehensive evidence for the value of relational and structural embeddedness, the relational and structural embeddedness hypotheses of alliance formations are limited because they lead to rather implausible predictions. According to the logic of relational and structural embeddedness, preexisting alliances should persist permanently, and two indirectly connected firms should form a direct alliance over time. As a result, alliance networks must evolve to become denser and more cohesive in the direction determined by current relationships. However, in reality, some firms terminate even long-term alliances (Greve, Mitsuhashi, \& Baum, 2013), and prefer strangers to embedded others as alliance partners (Baum, Rowley, Shilpilov, \& Chuang, 2005). These discrepancies reveal theoretical limitations in the network embeddedness approach and prompt us to clarify when and why firms do not prefer relationally or structurally embedded others as alliance partners.

The objective of this study is to examine the characteristics of alliance networks that inhibit alliance formation with embedded others. This study considers that the process of alliance formation includes two stages: choice set formation and partner selection. Relational and structural embeddedness provide firms with a choice set consisting of multiple embedded potential partners (i.e., options), but actual partner selection is a function of the characteristics of the choice sets given by relational and structural embeddedness. One focus of this study is on 
two characteristics of a choice set: the size of the choice set and the variation in the options' embeddedness with the focal firm. I propose that a choice set above a certain threshold in size and with sufficiently low variation in terms of the options' embeddedness enables firms to recognize several options, which increases uncertainty about these options and inhibits alliance formation. Empirical tests of the data on code-sharing dynamics in the global airline industry from 1994 to 2006 support these predictions and demonstrate that choice sets provided by relational and structural embeddedness have a significant influence on alliance formation.

This study has advantages over previous theoretical approaches to network embeddedness. Alliance networks essentially consist of multiple firms and ties (Borgatti \& Foster, 2003); thus, they generate a group of options rather than a single promising option for alliance formation. However, previous studies have had a limited focus on relationally or structurally embedded pairs of firms and their degrees of embeddedness, so we know little about how firms respond to multiple potential embedded partners for alliance formation. This study resolves this limitation by shifting attention from a dyad to the set, and considers relational and structural embeddedness as drivers of a partner choice set.

\section{Theory and Hypotheses}

\subsection{Partner Choice Sets Given by Network Embeddedness}

The primary purpose of alliance formation is to pool resources. For efficient and stable resource access, firms seek alliance partners with little uncertainty regarding their resources and capabilities, as well as those that can be guaranteed to behave in a trustworthy manner (i.e., are reliable). A network embeddedness approach proposes two types of search for such alliance partners: searches through relational embeddedness, which indicates prior alliance experience with other firms, and searches through structural embeddedness, which indicates current common partnerships with other firms. Two relationally or structurally embedded firms have less uncertainty about each other's capabilities and reliability (Gulati, 1995, 1998; Uzzi, 1996). First, two embedded firms can access information promptly about each other's resources and capabilities, based on their prior alliance experience or via common partners, which reduces uncertainty regarding each other's resources and capabilities (Li \& Rowley, 2002; Shipilov et al., 2006). This easy access to information about potential partners saves firms effort and time in finding appropriate alliance partners with little uncertainty. Second, through either emotional intimacy or the existence of reputational referrals, two embedded firms can restrain each other's opportunistic behaviors, reducing their uncertainty about each other's reliability. Firms with a long prior partnership are trustworthy and exchange fine-grained information or tacit knowledge (Tsai \& Ghoshal, 1998; Uzzi, 1996). Firms that are indirectly connected via several common partners are less likely to behave opportunistically because of potential threats to their reputation that could circulate among common partners and have a negative influence on partnerships with them (Moran, 2005; Uzzi, 1996). Given these advantages, the literature on network embeddedness considers relational and structural embeddedness to be the primary tools for seeking alliance partners, and the extent of relational (i.e., prior partnership duration) and structural embeddedness (i.e., number of common partners) between firms is a primary determinant of interfirm alliance formation (Tsai \& Ghoshal, 1998; Uzzi, 1996).

However, despite the importance of relational and structural embeddedness, these may not lead directly to interfirm alliance formation. There are three reasons for this. First, alliance networks essentially consist of multiple firms and ties (Borgatti \& Foster, 2003), so relational and structural embeddedness offer firms multiple potential partners. Therefore, alliance formation with embedded others necessarily prompts consideration of a group of potential partners, and its mechanisms should go beyond the dyadic level. Second, alliance formation is an important decision for firms, not only because it affects the quality of resources that firms exchange but also because termination of alliances with opportunistic partners or those with inappropriate competence entails significant costs for a renewed search (Burt, 2001). Such decisions fundamentally consist of generating multiple options, comparing and assessing each of these, and finding a promising option that serves the managers' interests. If network embeddedness provides firms with multiple potential partners, then the process of comparison and assessment of the multiple options will affect alliance formation. Third, in reality, firms do not form alliances with all embedded potential partners; rather, they select some and pass over others. Therefore, network embeddedness provides firms with a partner choice set in alliance formation processes, but actual partner selection may follow different mechanisms based on the characteristics of the choice set.

In this regard, this study proposes two types of partner choice set: an $R E$ choice set, which indicates a partner choice set driven by relational embeddedness, and an $S E$ choice set, which captures a partner choice set driven by structural embeddedness. The RE choice set consists of other firms, namely RE options, that have had prior alliance partnerships with the focal firm in the previous five years. The SE choice set consists of other firms, 
namely SE options, that are connected with the focal firm via their current common partners.

\subsection{Effects of Multi-Option Recognizability on Alliance Formation}

Having a choice set facilitates rational choice based on comparisons between options. However, contrary to some intuitions, having a large choice set may not necessarily lead to a satisfactory decision. Indeed, an argument concerning the paradox of choice about consumer behavior suggests that consumers tend not to buy products when there is a large number of purchasing options because the number of options they need to reject increases the expected opportunity costs and the loss of potential gains they could obtain from the abandoned options (Schwartz, 2004). The attention-based view also argues that boundedly rational managers are prone to attend selectively to the limited number of options to facilitate accurate and efficient processing of information in decision making, so managers cannot take full advantage of recognizing many options (Ocasio, 1997).

Given these possibilities, this study predicts that firms are less likely to engage in alliance formation with RE or SE options when they recognize multiple options within the RE or SE choice sets. This multi-option recognizability inhibits firms' partner selection within the choice sets in several ways. First, it complicates decision-making processes and increases the level of uncertainty about each option's resources and capabilities. In decision-making processes, managers develop implicit comparative matrices to compare and assess the resources and capabilities of each option (Maroun, 1991). With an increased number of comparable alternatives, the comparative matrices are likely to be large, with several types of information missing. Because further information is necessary to assess each option, uncertainty about resources and the capabilities of options will increase. Second, an increased number of comparable alternatives for each option leads to uncertainty regarding the reliability of options. This is because the firms have many alternatives with the same sources of reliability (i.e., emotional intimacy or reputational referrals), and thus may not give substantial weight to these advantages. Consequently, the primary reason for alliance formations with RE or SE options is to reduce these uncertainties; however, firms cannot take full advantage of this with increased multi-option recognizability.

Moreover, decision makers tend to judge the effectiveness of each option based on disadvantages rather than advantages (Maheswaran \& Meyerslevy, 1990), and it is typical for an option to have both. Thus, comparison processes with multiple targets increase managers' attention to the defects or weaknesses of each option, decreasing its perceived value (Skowronski \& Carlston, 1987). In addition, with multi-option recognizability in $\mathrm{RE}$ or SE choice sets, decision makers must abandon many alternatives after a decision to form an alliance, and with them some potential value. These expected opportunity costs result in regrets about missed additional gains and the choice made (Larrick, 1993). Reducing opportunity costs by selecting all possible partners is possible; however, firms will not entertain such decisions because the cost of forming and maintaining multiple alliances would accrue linearly (Burt, 2002).

Based on the above arguments, I develop hypotheses about the characteristics of RE or SE choice sets affecting firms' multi-option recognizability. Two characteristics of the choice sets are introduced in this study: size (i.e., the number of options) and variation in the embeddedness of the options within them.

\subsubsection{Choice Set Size}

Multi-option recognizability increases with the number of options within a choice set because firms have more opportunities to recognize options with a larger choice set. A large RE or SE choice set provides firms with many comparison targets for partner selection. Various comparative aspects of multiple RE or SE options are likely to highlight each option's weaknesses, increasing the level of uncertainty about their resources and capabilities as well as generating opportunity costs for diverse gains. These losses will not be offset by the expected trustworthiness of RE or SE options caused by emotional intimacy or reputational referrals because all options within the choice set have the same source of trustworthiness.

However, an exceedingly small RE or SE choice set may also inhibit partner selection in other ways. Firms with small choice sets may doubt the quality of their options because of insufficient bases of comparison for partner selection. The lack of comparison bases in decision-making processes devalues each option (Bazerman, Loewenstein, \& White, 1992). Thus, this study predicts that firms need a minimum number of RE or SE options to select one as an alliance partner, but a large number of options beyond a certain threshold inhibits alliance formation.

Hypothesis 1a. A focal firm's partner selection within an RE choice set has an inverted U-shaped relationship with the size of the set.

Hypothesis 1 . A focal firm's partner selection within an SE choice set has an inverted U-shaped relationship with the size of the set. 


\subsubsection{Variation in Option Embeddedness}

Managers do not attend equally to all options within a choice set (Hoffman \& Ocasio, 2001). For more efficient decision making, they attend primarily to obvious options, and if these are satisfactory alliance partners, then they stop the search process and ignore the alternatives (Argote \& Greve, 2007). This study considers that variations in the embeddedness of options assist these processes, facilitating partner selection from the choice set.

If the firm has had a particularly close prior alliance experience (i.e., high relational embeddedness) with a certain RE option or a high number of common partners (i.e., high structural embeddedness) with a certain SE option, the firm can most easily access information about these options. This accessibility allows the firm to recognize the resources and capabilities of options clearly, decreasing its uncertainty regarding theses aspects. Moreover, the firm may have high expectations that these options will be more cooperative because of their high level of emotional intimacy or reputational referrals (Uzzi, 1996). Hence, with a high level of variation in option embeddedness within the choice set, firms can easily identify more promising options and have low uncertainty regarding their resources and reliability.

On the other hand, with decreased variation in the embeddedness of options, the firm's options are likely to be equally available to all; thus, the firm is likely to recognize multiple options. In addition, all of these options can provide the firm with intimate or reputational referrals to a similar degree, so the firm may have difficulty identifying more trustworthy options within the set. Therefore, this study predicts:

Hypothesis 2a. A focal firm is less likely to choose alliance partners from an RE choice set if the options have low variation in relational embeddedness.

Hypothesis 2b. A focal firm is less likely to choose alliance partners from an SE choice set if the options have low variation in structural embeddedness.

For consistency with the above arguments, the chosen RE or SE options should have only a few other predominant RE or SE options within the same choice set. If there are many other RE or SE options with greater relational or structural embeddedness than the focal option, they may draw the focal firm's attention away from the focal option, which is thus less likely to be considered as an alliance partner. Similar mechanisms may affect other RE or SE options with equal relational or structural embeddedness to the focal option. When there are many other such options in the same choice set, the focal firm will have the same access to information about the others as it has to information about the focal option. This makes it difficult for the focal option to attract the primary attention of the focal firm. Moreover, because the focal firm has many reliable alternatives to the focal option with intimate or reputational referrals, the focal option's reliability as an alliance partner may be devalued. Therefore, the following hypotheses are proposed.

Hypothesis 3a. A focal RE option is less likely to be selected by a focal firm as an alliance partner if its RE choice set includes many other options with greater or equal relational embeddedness.

Hypothesis 3b. A focal SE option is less likely to be selected by a focal firm as an alliance partner if its SE choice set includes many other options with greater or equal structural embeddedness.

\section{Methods}

\subsection{Sample}

I tested the hypotheses in the context of code-share alliances in the global airline industry using data collected from 1994 to 2006. A code-share alliance is a typical business alliance in the global airline industry, whereby different airlines sell space on the same flight (Lazzarini, 2007). Using the Airline Business Alliance Survey, Air Transport World, IATA World Air Transport Statistics and ICAO Airline Database, I first identified commercial airlines that operated international flights that were ranked in the top 100 firms in terms of sales at least once from 1994 to 2006. I then excluded airlines for which operational and financial data were not available. The final sample included 72 airlines in 47 countries with a total market share of $71.7 \%$ in 2006 revenue passenger kilometers. Therefore, the sample is representative of the entire industry.

There were two major reasons for the choice of this context for hypothesis testing. First, I conducted semistructured interviews with the managers of two international airlines and confirmed that code-share alliances could provide not only pool traffic capacity but also access to information about potential partners. Therefore, they use code sharing as a channel to search for potential partners. Second, because code-share alliances are a critical tool in airline strategy for resource pooling and exchange, as well as a major driver of performance, it is important to select alliance partners with low uncertainty. Hence, high uncertainty about potential partners is a 
strong deterrent to partner selection. These considerations are pertinent for testing the effects of the choice set of options for alliance decisions. Figure 1 shows the code-share alliance networks in 2000.

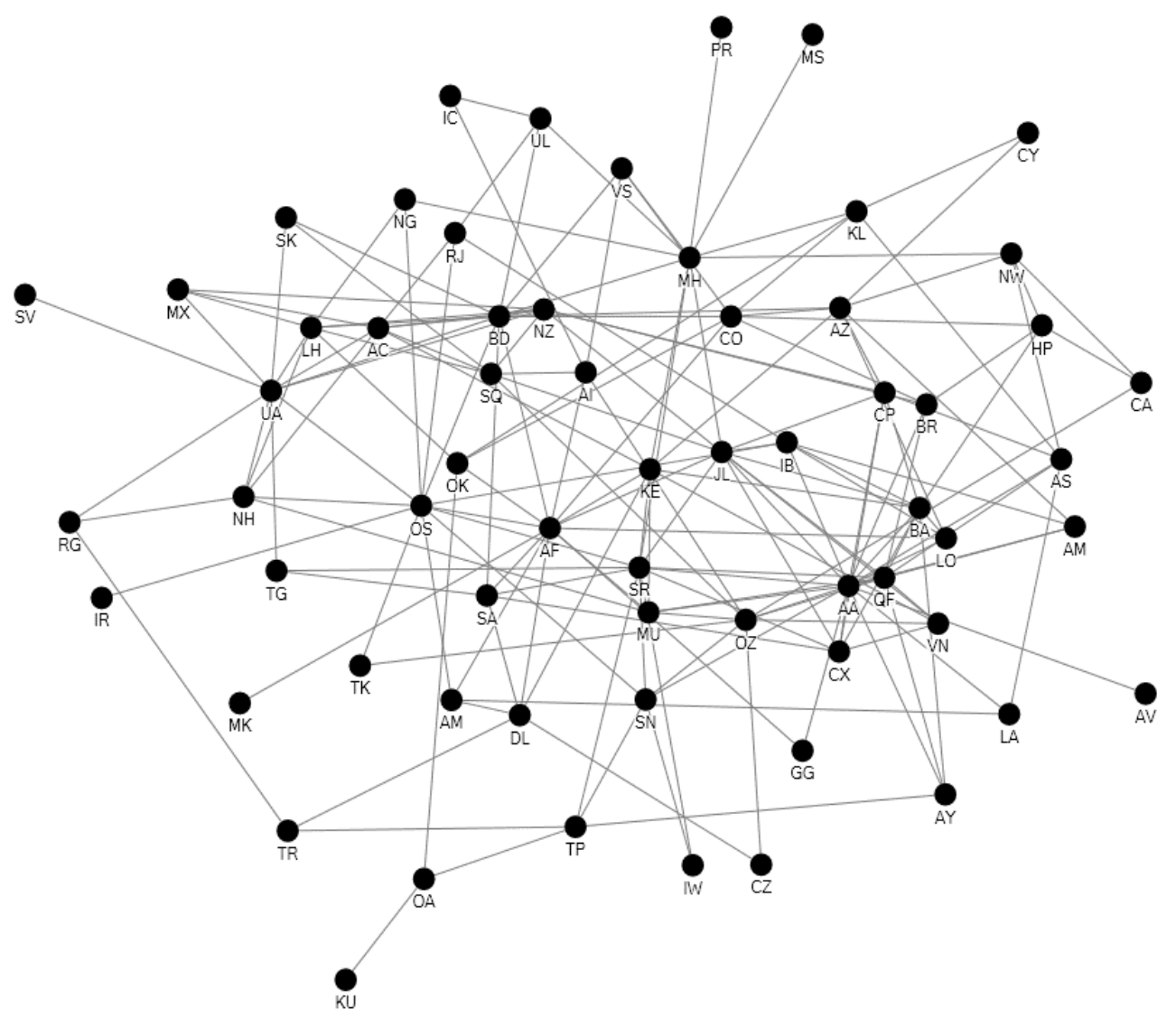

Figure 1. The code-share alliance networks in 2000

\subsection{Modeling Framework}

To test the proposed hypotheses, I developed RE and SE choice sets in two steps. In the first step, I identified a dyad consisting of a focal firm and its RE and SE options with relatively high market complementarity according to the industry average. This step is necessary because, as mentioned above, the primary purpose of alliance formation is to pool resources. Even two highly embedded firms may not consider each other to be potential partners if they have low market complementarities and little chance of cooperation. Market complementarity in a dyad was calculated following Mitsuhashi and Greve (2009) as follows:

$$
\text { Market Complementarity }=\frac{|A \cup B-(A \cap B)|}{|A \cup B|}
$$

Where $\mathrm{A}$ and $\mathrm{B}$ are the regional markets (i.e., routes) serviced at time $\mathrm{t}$ by the two firms.

In the second step, for each focal firm, I identified the RE options by specifying prior alliance partners in the previous five years that had not formed alliances at time $t$ (i.e., prior partners from $t-5$ to $t-1$ ). I used the previous five years to consider the effects of time decay, which also helped to overcome a left-censoring problem by including the year when code sharing between global airlines began (1989). I also identified the SE options by identifying firms that were indirectly connected with a focal firm via common partners. For each focal firm, I identified a group of RE and SE options (i.e., choice sets) at time t. I then excluded from the dataset isolated firms with no options or only one option. For all analyses, I used the RE and SE choice sets separately because alliance formations based on each set have different meanings. The former indicates the reformation of an alliance, while the latter indicates a new alliance with strangers. The mean choice set size was 4.88 options per RE choice set and 18.75 options per SE choice set. 


\subsection{Statistical Method and Analysis}

I used maximum-likelihood logit regression to model partner selection within the RE or SE choice sets for hypotheses 1 and 2 using the "xtlogit" command in Stata 13. For these models, I used a random-effects model because a Hausman test, which was conducted to choose the appropriate model formulation between fixed-and random-effects models, supported the random-effects specification.

For hypothesis 3, I adopted two methods of sampling. The first method was to identify focal firms that engaged in actual alliance formations from RE or SE choice sets at time $t$ and all of their RE or SE options, and then include them in the sample. However, with this method, focal firms have significantly different numbers of options, and thus the probabilities of selection of options are not equivalent for each focal firm. To address these problems, I used a second method, wherein I randomly chose a case (i.e., a pair comprising a focal firm and its chosen RE or SE option) and 50 control observations (i.e., counterfactual pairs) per case (Rogan \& Sorenson, 2014). I randomly drew a sample 1000 times and used the estimation results with the highest log-likelihood value and the best model fit. Using these two sample types, I conducted a conditional logit regression because testing hypotheses was associated with modeling multiple and unordered choices. A focal firm can choose multiple alliance partners from its choice set. Previous studies have argued that a conditional logit model is a powerful tool for investigating decisions because it provides measures to compare options directly (Greve, 2000). I used the "clogit" command grouped according to focal firm in Stata 13 for these analyses. I also applied the robust option for standard errors because of internal correlations.

\subsection{Measures}

\subsubsection{Dependent Variable}

For hypotheses 1 and 2, I developed a dichotomous variable coded as 1 if the focal firm forms alliances with any option within the RE or SE choice set at time $t+1$ and 0 otherwise. Thus, the unit of analysis for these hypotheses is a focal firm. For hypothesis 3, I used dyads of a focal firm and each of its focal RE or SE options as the units of analysis. I coded the dyad as 1 if the focal pair had formed an alliance at time $t+1$ and 0 otherwise.

\subsubsection{Independent Variables}

To test the effects of choice set size in hypothesis 1, I counted the number of prior partners of the focal firm in the previous five years (i.e., RE options) and the number of the focal firm's indirectly connected firms (i.e., SE options) at time t. Because hypothesis 1 predicted an inverted U-shape relationship between choice set size and partner selection within the choice set, I also included the square of their values.

To test hypothesis 2, I developed variation in option embeddedness using coefficient variations in the durations of the prior alliances of RE options and the numbers of common partners of SE options. To calculate prior alliance duration between a focal firm and each of its RE options, I adopted a time-decay function based on the duration of previous alliances in years. To calculate structural embeddedness when one common partner offered the focal firm multiple options, I adopted decimal values for the number of common partners by dividing the number of common partners (i.e., one) by the number of multiple SE options. This is necessary because a common partner would have a low probability of transferring information about each indirectly connected firm to the focal firm. Increased variation in this coefficient led to increased relational and structural embeddedness variation in choice sets, thus decreasing multi-option recognizability for the focal firm.

For hypothesis 3, I entered other RE or SE options with greater embeddedness (GE) (other RE or SE options with $G E$ ) and those with equal embeddedness (EE) (other RE or SE options with EE), respectively. I identified other options with prior alliance duration or number of common partners greater than or equal to that of the focal option at time $t$ within the same RE or SE choice set. I then counted the number of these options at time $t$.

\subsubsection{Control Variable}

First, I entered several variables to control for organizational characteristics. I controlled for firm age, performance as measured by load factor, and size as measured by the number of markets entered at time t. I also included the number of alliances terminated at time $t$ because alliance termination may lead to a search for alternatives. Because of the different units of analysis, I used these characteristics of focal firms for hypotheses 1 and 2 and those of focal options for hypothesis 3.

Second, I controlled for several relational aspects between a focal firm and a focal option. I entered status dissimilarity as measured by differences in eigenvector centrality. Market complementarity is also included, using the aforementioned measures suggested by Mitsuhashi and Greve (2009). In addition, options with resource compatibility attract greater attention from a focal firm and acquire more opportunities for alliance 
formation. In code sharing, because large fleets of aircraft are critical resources, I controlled for similarity in the number of large fleets. I split the fleets of firms included in the sample into three categories based on their seating capacity, and calculated the difference in the number of large fleets. I used these averaged values of RE or SE options for hypotheses 1 and 2. I also entered relational and structural embeddedness between a focal firm and its focal option, but I did not include these variables to test hypotheses 1 and 2 because these are reflected in their independent variables. Finally, because some options are in both the RE and the SE set (options shared in both sets), I controlled for this by counting the number of these options for hypotheses 1 and 2 and by coding a focal option as 1 if it was shared by both sets and 0 otherwise.

Third, during the observation periods, industry consortiums including Atlantic Excellence, Wings, Qualifier, Star Alliance, Oneworld, and Sky Team became platforms for resource mobilization. Because highly compatible resources and common goals facilitate the development of code sharing between consortium members (Lazzarini, 2007), I needed to control for these effects carefully. Thus, I included variables representing membership of the same consortium by a focal firm and its focal option (same consortium membership of $F O$ ) and that of a focal firm and its common partner(s) or of a common partner(s) and the focal option (same consortium membership of indirect tie). For hypothesis 3, I counted these occurrences in RE or SE choice sets for hypotheses 1 and 2, and coded the variable as 1 for such memberships and 0 otherwise.

\section{Results}

Tables 1a, 1b, and 1c show the descriptive statistics and correlations of variables used to test each prediction. To assess the potential threat of multicollinearity, I estimated the variance inflation factors (VIFs) and found that the highest VIF for all models was 2.18, below the critical point of 10 . Therefore, multicollinearity had little effect (Belsley, Kuh, \& Welsch, 1980).

Table 1a. Descriptive statistics for partner selection within $\mathrm{RE}$ and $\mathrm{SE}$ choice sets $(\mathrm{N}=830)$

\begin{tabular}{|c|c|c|c|c|c|c|c|c|c|c|c|c|c|c|c|c|c|c|c|c|c|c|c|}
\hline & Variables & Mean & SD & 1 & 2 & 3 & 4 & 5 & 6 & 7 & 8 & 9 & 10 & 11 & & & & & & & & & \\
\hline 1 & Partner selection within RE choice set & 0.14 & 0.34 & & & & & & & & & & & & & & & & & & & & \\
\hline 2 & Partner selection within SE choice set & 0.42 & 0.49 & .26 & & & & & & & & & & & & & & & & & & & \\
\hline 3 & Focal firm's log-transformed age & 3.75 & 0.69 & .11 & .21 & & & & & & & & & & & & & & & & & & \\
\hline 4 & Focal firm's load factors & 68.94 & 5.51 & .07 & .20 & .01 & & & & & & & & & & & & & & & & & \\
\hline 5 & Number of markets entered by focal firm & 36.05 & 25.14 & .06 & .27 & .17 & .24 & & & & & & & & & & & & & & & & \\
\hline 6 & Number of alliances terminated by focal firm & 0.83 & 1.45 & .15 & .31 & .19 & .20 & .18 & & & & & & & & & & & & & & & \\
\hline 7 & Status dissimilarity ${ }^{\mathrm{RE}}$ & 0.10 & 0.09 & .09 & .13 & .03 & -.01 & .06 & .07 & & & & & & & & & & & & & & \\
\hline 8 & Market complementarity ${ }^{\mathrm{RE}}$ & 0.98 & 0.02 & .11 & -.13 & -.08 & -.19 & -.23 & -.05 & .01 & & & & & & & & & & & & & \\
\hline 9 & Difference in the number of large fleets ${ }^{\mathrm{RE}}$ & 68.13 & 50.07 & -.02 & .11 & .15 & .00 & .25 & .12 & .01 & -.24 & & & & & & & & & & & & \\
\hline 10 & Options shared by both sets ${ }^{\mathrm{RE}}$ & 0.63 & 1.08 & .33 & .26 & .14 & .06 & .13 & .35 & .20 & .12 & .02 & & & & & & & & & & & \\
\hline 11 & Same consortium membership of $\mathrm{FO}^{\mathrm{RE}}$ & 1.56 & 2.70 & .16 & .35 & .23 & .29 & .37 & .33 & .13 & -.17 & .18 & .14 & & & & & & & & & & \\
\hline 12 & Same consortium membership of indirect tie ${ }^{\mathrm{RE}}$ & 0.44 & 0.87 & .25 & .32 & .17 & .20 & .24 & .43 & .09 & -.09 & .15 & .49 & .54 & & & & & & & & & \\
\hline 13 & Choice set size ${ }^{\mathrm{RE}}$ & 4.88 & 4.41 & .26 & .25 & .15 & .02 & .15 & .27 & .17 & .29 & -.11 & .64 & .03 & -.28 & & & & & & & & \\
\hline 15 & Status dissimilarity ${ }^{\mathrm{SE}}$ & 0.10 & 0.08 & .03 & .08 & .02 & -.06 & .10 & .07 & .61 & .04 & -.05 & .17 & .02 & -.02 & .29 & .01 & & & & & & \\
\hline 16 & Market complementarity ${ }^{\mathrm{SE}}$ & 0.98 & 0.02 & .10 & -.05 & -.08 & -.10 & -.41 & .00 & .09 & .48 & -.07 & .10 & -.05 & .07 & .07 & -.12 & -.03 & & & & & \\
\hline 17 & Difference in the number of large fleets ${ }^{\mathrm{SE}}$ & 56.40 & 39.05 & -.02 & .14 & .15 & .18 & .42 & .18 & -.02 & -.19 & .60 & .07 & .19 & -.01 & .03 & .19 & .01 & -.26 & & & & \\
\hline 18 & Shared options in both sets ${ }^{\mathrm{SE}}$ & 1.27 & 1.54 & .25 & .26 & .15 & .09 & .33 & .36 & .16 & -.05 & .03 & .76 & .07 & -.64 & .54 & .19 & .18 & -.20 & .17 & & & \\
\hline 19 & Same consortium membership of $\mathrm{FO}^{\mathrm{SE}}$ & 2.35 & 4.17 & .16 & .37 & .22 & .29 & .26 & .34 & .11 & -.16 & .13 & .14 & .90 & .49 & .17 & .40 & .07 & -.03 & .17 & .18 & & \\
\hline 20 & Same consortium membership of indirect tie $\mathrm{e}^{\mathrm{SE}}$ & 7.95 & 8.44 & .17 & .43 & .22 & .28 & .13 & .33 & .12 & -.16 & .15 & .15 & .68 & .53 & .18 & .45 & -.04 & .13 & .13 & .09 & .71 & \\
\hline 21 & Choice set size $\mathrm{S}^{\mathrm{SE}}$ & 18.75 & 12.26 & .24 & .52 & .24 & .28 & .13 & .38 & .19 & -.09 & .10 & .26 & .31 & -.19 & .28 & .57 & -.02 & .17 & .06 & .18 & .20 & .30 \\
\hline 22 & Variation in option embeddedness ${ }^{\mathrm{SE}}$ & 1.80 & 1.24 & -.07 & -.09 & .03 & -.10 & -.13 & -.09 & -.08 & -.03 & -.05 & -.08 & -.09 & .01 & -.03 & -.07 & -.03 & -.05 & -.01 & -.22 & -.07 & $\begin{array}{lll}-.15 & -.21\end{array}$ \\
\hline
\end{tabular}

Note. ${ }^{\mathrm{RE}}$ and ${ }^{\mathrm{SE}}$ indicate characteristics of RE and $\mathrm{SE}$ choice sets, respectively. 
Table 1b. Descriptive statistics for selection of RE options $(\mathrm{N}=3834)$

\begin{tabular}{|c|c|c|c|c|c|c|c|c|c|c|c|c|c|c|c|c|}
\hline Variables & Mean & SD & 1 & 2 & 3 & 4 & 5 & 6 & 7 & 8 & 9 & 10 & 11 & 12 & 13 & 14 \\
\hline 1 Selection of RE options & 0.62 & 0.49 & & & & & & & & & & & & & & \\
\hline 2 Option's log-transformed age ${ }^{\mathrm{RE}}$ & 3.92 & 0.52 & .03 & & & & & & & & & & & & & \\
\hline 3 Option's load factors ${ }^{\mathrm{RE}}$ & 71.82 & 27.61 & -.03 & -.02 & & & & & & & & & & & & \\
\hline 4 Number of markets entered by option ${ }^{\mathrm{RE}}$ & 44.21 & 28.15 & .03 & .20 & .00 & & & & & & & & & & & \\
\hline 5 Number of alliances terminated by option ${ }^{\mathrm{RE}}$ & 1.56 & 1.96 & -.08 & .12 & -.04 & .10 & & & & & & & & & & \\
\hline 6 Status dissimilarity ${ }^{\mathrm{RE}}$ & 0.12 & 0.15 & -.04 & .04 & .00 & .05 & .03 & & & & & & & & & \\
\hline 7 Market complementarity ${ }^{\mathrm{RE}}$ & 0.47 & 0.47 & .07 & -.01 & .04 & $.22-$ & $-.03-$ & -.03 & & & & & & & & \\
\hline 8 Difference in the number of large fleets ${ }^{\mathrm{RE}}$ & 77.59 & 76.08 & 3.02 & .07 & -.02 & .17 & .07 & -.07 & .13 & & & & & & & \\
\hline 9 Relational embeddedness ${ }^{\mathrm{RE}}$ & 0.56 & 1.27 & -.34 & .05 & $-.02-$ & -.02 & .21 & $.05-$ & -.03 & .04 & & & & & & \\
\hline 10 Structural embeddedness ${ }^{\mathrm{RE}}$ & 0.21 & 0.74 & -.24 & .04 & .00 & .05 & .11 & .03 & .02 & .01 & .27 & & & & & \\
\hline 11 Options shared by both sets ${ }^{\mathrm{RE}}$ & 0.09 & 0.29 & -.30 & .04 & $.02-$ & -.03 & .15 & $.04-$ & -.30 & .01 & .31 & .39 & & & & \\
\hline 12 Same consortium membership of $\mathrm{FO}^{\mathrm{RE}}$ & 0.26 & 0.44 & .23 & .15 & .00 & .21 & $.02-$ & -.02 & .15 & .14 & -.09 & .03 & -.10 & & & \\
\hline 13 Same consortium membership of indirect tie ${ }^{\mathrm{RE}}$ & 0.08 & 0.28 & -.26 & .04 & -.00 & .05 & .11 & $.01-$ & -.03 & .06 & .32 & .57 & -.50 & .03 & & \\
\hline 14 Other options with $\mathrm{GE}^{\mathrm{RE}}$ & 4.03 & 3.73 & -.02 & -.01 & $-.01-$ & -.08 & -.03 & .07 & .00 & .06 & -.05 & .15 & .06 & .06 & -.05 & \\
\hline 15 Other options with $\mathrm{EE}^{\mathrm{RE}}$ & 2.81 & 1.83 & -.12 & -.06 & $-.02-$ & -.03 & .01 & .10 & -.01 & .03 & -.04 & .12 & .08 & $-.03-$ & -.10 & .41 \\
\hline
\end{tabular}

Table 1c. Descriptive statistics for selection of SE options $(\mathrm{N}=9054)$

\begin{tabular}{|c|c|c|c|c|c|c|c|c|c|c|c|c|c|c|c|c|}
\hline Variables & Mean & $\mathrm{SD}$ & 1 & 2 & 3 & 4 & 5 & 6 & 7 & 8 & 9 & 10 & 11 & 12 & 13 & 14 \\
\hline 1 Selection of SE options & 0.07 & 0.25 & & & & & & & & & & & & & & \\
\hline 2 Option's log-transformed age ${ }^{\mathrm{SE}}$ & 3.85 & 0.59 & .04 & & & & & & & & & & & & & \\
\hline 3 Option's load factors ${ }^{\mathrm{SE}}$ & 70.38 & 14.94 & .00 & .01 & & & & & & & & & & & & \\
\hline 4 Number of markets entered by option ${ }^{\mathrm{SE}}$ & 38.82 & 25.29 & .07 & .21 & .06 & & & & & & & & & & & \\
\hline 5 Number of alliances terminated by option ${ }^{\mathrm{SE}}$ & 1.21 & 1.61 & .07 & .15 & -.01 & .19 & & & & & & & & & & \\
\hline 6 Status dissimilarity ${ }^{\mathrm{SE}}$ & 0.11 & 0.15 & .03 & .03 & .01 & .06 & .01 & & & & & & & & & \\
\hline 7 Market complementarity ${ }^{\mathrm{SE}}$ & 0.36 & 0.46 & .05 & .06 & .07 & .24 & .07 & .03 & & & & & & & & \\
\hline 8 Difference in the number of large fleets ${ }^{\mathrm{SE}}$ & 62.12 & 65.95 & .03 & .09 & .02 & .23 & .09 & .03 & .19 & & & & & & & \\
\hline 9 Relational embeddedness ${ }^{\mathrm{SE}}$ & 0.11 & 0.60 & .16 & .06 & .01 & .06 & .15 & .05 & .03 & .09 & & & & & & \\
\hline 10 Structural embeddedness ${ }^{\mathrm{SE}}$ & 1.14 & 1.35 & .11 & .08 & .01 & .09 & .08 & .10 & .07 & .07 & .03 & & & & & \\
\hline 11 Options shared by both sets ${ }^{\mathrm{SE}}$ & 0.04 & 0.19 & .10 & .02 & .01 & .03 & .11 & .06 & -.14 & .04 & .45 & -.02 & & & & \\
\hline 12 Same consortium membership of $\mathrm{FO}^{\mathrm{SE}}$ & 0.07 & 0.25 & .28 & .06 & .02 & .03 & .08 & -.05 & .03 & -.01 & .14 & .25 & .04 & & & \\
\hline 13 Same consortium membership of indirect tie $\mathrm{SE}^{\mathrm{SE}}$ & 0.46 & 0.50 & .07 & .07 & .01 & .04 & .06 & .10 & .04 & .31 & .04 & .31 & -.01 & .24 & & \\
\hline 14 Other options with $\mathrm{GE}^{\mathrm{SE}}$ & 11.59 & 9.24 & -.11 & -.08 & .00 & -.16 & -.09 & $-.01-$ & -.08 & $-.05-$ & -.01 & -.67 & $-.03-$ & -.16 & -.14 & \\
\hline 15 Other options with $\mathrm{EE}^{\mathrm{SE}}$ & 6.02 & 3.69 & -.05 & .01 & .01 & .00 & .02 & $-.11-$ & -.05 & -.08 & -.01 & -.02 & .00 & -.06 & .08 & -.12 \\
\hline
\end{tabular}

Table 2 shows the results of testing hypotheses 1 and 2, using logit estimates for focal firms' selection of any option within RE or SE choice sets. Models 1 through 3 show the results for tests based on RE options, whereas models 4 through 6 report those of tests based on SE options. The results presented in models 2 and 5 show that the size of both RE and SE choice sets has significantly positive effects $(p<.001)$, while size squared has significantly negative effects $(\mathrm{p}<.01)$ on partner selection from the RE or SE choice sets. These results support hypothesis 1 . The results presented in models 3 and 6 show that high variation in option embeddedness produces significantly positive impacts on partner selection for both $\operatorname{RE}(\mathrm{p}<.1)$ and SE choice sets $(\mathrm{p}<.05)$, providing 
support for hypothesis 2 .

Table 2. Logit regression results for partner selection from RE and SE choice sets

\begin{tabular}{|c|c|c|c|c|c|c|c|c|c|}
\hline & & $\underline{\text { RE choice set }}$ & & & & $\underline{\mathrm{SE} \text { cho }}$ & oice s & & \\
\hline & Model 1 & Model 2 & Model 3 & Model & & Mode & el 5 & Mode & el 6 \\
\hline Firm's log-transformed age & 0.295 & 0.129 & 0.174 & 0.372 & $\dagger$ & 0.229 & & 0.214 & \\
\hline & $(0.25)$ & $(0.23)$ & $(0.24)$ & $(0.20)$ & & $(0.17)$ & & $(0.17)$ & \\
\hline Firm's load factors & 0.016 & 0.001 & 0.008 & 0.027 & & 0.011 & & 0.014 & \\
\hline & $(0.03)$ & $(0.03)$ & $(0.03)$ & $(0.02)$ & & $(0.02)$ & & $(0.02)$ & \\
\hline Number of markets entered by firm & $0.012 \dagger$ & 0.007 & 0.009 & 0.016 & $* *$ & 0.01 & $\dagger$ & 0.011 & $*$ \\
\hline & $(0.01)$ & $(0.01)$ & $(0.01)$ & $(0.01)$ & & $(0.01)$ & & $(0.01)$ & \\
\hline Number of alliances terminated by firm & -0.114 & $-0.140 \dagger$ & $-0.145 \dagger$ & 0.071 & & 0.069 & & 0.040 & \\
\hline & $(0.09)$ & $(0.08)$ & $(0.09)$ & $(0.08)$ & & $(0.08)$ & & $(0.08)$ & \\
\hline Status dissimilarity & -0.006 & 0.058 & -0.37 & 2.428 & & 2.855 & $\dagger$ & 2.836 & $\dagger$ \\
\hline & $(1.22)$ & $(1.22)$ & $(1.22)$ & $(1.53)$ & & $(1.66)$ & & $(1.59)$ & \\
\hline Market complementarity & $-1.625 * *$ & -0.756 & $-1.569 *$ & 0.678 & & 0.744 & & 0.688 & \\
\hline & $(0.52)$ & $(0.58)$ & $(0.65)$ & $(0.48)$ & & $(0.46)$ & & $(0.43)$ & \\
\hline Difference in the number of large fleets & $-0.005 \dagger$ & $-0.006 \dagger$ & $-0.005 \dagger$ & -0.002 & & $-4 . E-05$ & & 3.E-04 & \\
\hline & $(0.00)$ & $(0.00)$ & $(0.00)$ & $(0.00)$ & & $(0.00)$ & & $(0.00)$ & \\
\hline Options shared by both sets & $0.685 * * *$ & $0.610 * * *$ & $0.514 * *$ & 0.280 & $* * *$ & 0.164 & $*$ & 0.200 & * \\
\hline & $(0.14)$ & $(0.16)$ & $(0.16)$ & $(0.08)$ & & $(0.08)$ & & $(0.08)$ & \\
\hline Same consortium membership of FO & 0.034 & 0.015 & 0.016 & -0.003 & & 0.074 & $*$ & 0.09 & $*$ \\
\hline & $(0.06)$ & $(0.06)$ & $(0.06)$ & $(0.03)$ & & $(0.04)$ & & $(0.04)$ & \\
\hline Same consortium membership of indirect tie & 0.073 & 0.026 & 0.101 & 0.085 & $* * *$ & -0.004 & & -0.020 & \\
\hline & $(0.17)$ & $(0.16)$ & $(0.16)$ & $(0.02)$ & & $(0.03)$ & & $(0.02)$ & \\
\hline Choice set size & & $0.297 * * *$ & $0.082 \dagger$ & & & 0.194 & $* * *$ & 0.116 & $* * *$ \\
\hline & & $(0.08)$ & $(0.05)$ & & & $(0.04)$ & & $(0.02)$ & \\
\hline Squared choice set size & & $-0.011 * *$ & & & & -0.002 & $* *$ & & \\
\hline & & $(0.00)$ & & & & $(0.00)$ & & & \\
\hline Variation in option embeddedness & & & $0.344 \dagger$ & & & & & 0.278 & \\
\hline & & & $(0.18)$ & & & & & $(0.11)$ & \\
\hline Constant & $-4.357 \dagger$ & -3.702 & $-4.005 \dagger$ & -5.465 & $* *$ & -6.042 & $* * *$ & -6.302 & $* * *$ \\
\hline & $(2.32)$ & $(2.27)$ & $(2.26)$ & $(1.95)$ & & $(1.78)$ & & $(1.78)$ & \\
\hline Log likelihood & -260.33 & -253.25 & -256.80 & -410.96 & & -382.73 & & -383.55 & \\
\hline $\mathrm{N}$ & 830 & 830 & 830 & 830 & & 830 & & 830 & \\
\hline
\end{tabular}

Note. Standard errors are in parentheses: $\uparrow \mathrm{p}<.10,{ }^{*} \mathrm{p}<.05,{ }^{* *} \mathrm{p}<.01,{ }^{* * *} \mathrm{p}<.001$; Year dummy variables are included in all models but not shown for the sake of space.

Table 3 provides conditional logit analysis results for selection of focal options by focal firms using the sample of all observations (in models 7, 8, 10, and 11) and random sampling (in models 9 and 12). Results show that a focal option is less likely to be chosen as an alliance partner by the focal firm if there are many other RE or SE options with relational or structural embeddedness greater than or equal to that of the focal option, providing strong support for hypothesis 3. Additionally, results show that firms do not select RE options as alliance partners if those options have high relational or structural embeddedness. This demonstrates that a degree of uncertainty between firms may be required for alliance reformation. 
Table 3. Conditional logit regression results for selection of RE and SE options

\begin{tabular}{|c|c|c|c|c|c|c|}
\hline \multirow[b]{2}{*}{ Variables } & \multicolumn{3}{|c|}{$\underline{\mathrm{RE} \text { choice set }}$} & \multicolumn{3}{|c|}{$\underline{\text { SE choice set }}$} \\
\hline & Model 7 & Model 8 & Model 9 & Model 10 & Model 11 & Model 12 \\
\hline \multirow[t]{2}{*}{ Option's log-transformed age } & -0.028 & -0.055 & -0.005 & 0.090 & 0.087 & -0.028 \\
\hline & $(0.08)$ & $(0.08)$ & $(0.14)$ & $(0.09)$ & $(0.09)$ & $(0.13)$ \\
\hline \multirow[t]{2}{*}{ Option's load factors } & -0.003 & -0.003 & -0.007 & -0.003 & -0.003 & 0.010 \\
\hline & $(0.00)$ & $(0.00)$ & $(0.01)$ & $(0.01)$ & $(0.01)$ & $(0.02)$ \\
\hline \multirow[t]{2}{*}{ Number of markets entered by option } & 0.001 & 0.001 & 2.E-04 & 0.002 & 0.002 & 0.004 \\
\hline & $(0.00)$ & $(0.00)$ & $(0.00)$ & $(0.00)$ & $(0.00)$ & $(0.00)$ \\
\hline \multirow[t]{2}{*}{ Number of alliances terminated by option } & -0.014 & -0.011 & -0.003 & $0.059^{*}$ & $0.059^{*}$ & $0.085^{*}$ \\
\hline & $(0.02)$ & $(0.02)$ & $(0.04)$ & $(0.03)$ & $(0.03)$ & $(0.04)$ \\
\hline \multirow[t]{2}{*}{ Status dissimilarity } & -0.176 & -0.212 & $-1.404^{*}$ & $1.189^{* * * *}$ & $1.189 * * *$ & 0.890 \\
\hline & $(0.36)$ & $(0.36)$ & $(0.68)$ & $(0.36)$ & $(0.36)$ & $(0.58)$ \\
\hline \multirow[t]{2}{*}{ Market complementarity } & 0.050 & 0.044 & 0.033 & $0.459 * * *$ & $0.461 * * *$ & $0.521 *$ \\
\hline & $(0.11)$ & $(0.11)$ & $(0.19)$ & $(0.13)$ & $(0.13)$ & $(0.20)$ \\
\hline \multirow[t]{2}{*}{ Difference in number of large fleets } & 0.001 & 9.E-04 & 0.001 & 0.001 & 0.001 & $-4 . \mathrm{E} .04$ \\
\hline & $(0.00)$ & $(0.00)$ & $(0.00)$ & $(0.00)$ & $(0.00)$ & $(0.00)$ \\
\hline \multirow[t]{2}{*}{ Relational embeddedness } & $-0.516^{* * *}$ & $-0.556^{* * *}$ & $-0.510^{* * *}$ & $0.277 * * *$ & $0.274 * * *$ & $0.308 * * *$ \\
\hline & $(0.04)$ & $(0.04)$ & $(0.07)$ & $(0.05)$ & $(0.05)$ & $(0.08)$ \\
\hline \multirow[t]{2}{*}{ Structural embeddedness } & $-0.302 * * *$ & $-0.254 * * *$ & $-0.303^{*}$ & $0.130 * * *$ & -0.018 & -0.036 \\
\hline & $(0.08)$ & $(0.07)$ & $(0.13)$ & $(0.04)$ & $(0.07)$ & $(0.11)$ \\
\hline \multirow[t]{2}{*}{ Options shared in both sets } & $-1.028 * * *$ & $-0.985^{* * *}$ & $-1.051 * *$ & $0.855^{* * *}$ & $0.848 * * *$ & $0.942 * *$ \\
\hline & $(0.20)$ & $(0.20)$ & $(0.36)$ & $(0.20)$ & $(0.20)$ & $(0.29)$ \\
\hline \multirow[t]{2}{*}{ Same consortium membership of FO } & $1.419 * * *$ & $1.372 * * *$ & $1.480 * * *$ & $2.478 * * *$ & $2.480 * * *$ & $2.604 * * *$ \\
\hline & $(0.13)$ & $(0.13)$ & $(0.22)$ & $(0.15)$ & $(0.16)$ & $(0.25)$ \\
\hline \multirow[t]{2}{*}{ Same consortium membership of indirect tie } & $-0.976^{* * *}$ & $-0.872 * * *$ & $-1.797 * * *$ & $0.310^{*}$ & $0.315^{* *}$ & 0.251 \\
\hline & $(0.22)$ & $(0.22)$ & $(0.40)$ & $(0.12)$ & $(0.12)$ & $(0.19)$ \\
\hline \multirow[t]{2}{*}{ Other options with GE } & & $-0.077 * * *$ & $-0.060 *$ & & $-0.027 * *$ & $-0.035 \dagger$ \\
\hline & & $(0.02)$ & $(0.03)$ & & $(0.01)$ & $(0.02)$ \\
\hline \multirow[t]{2}{*}{ Other options with EE } & & $-0.085 * *$ & $-0.109 *$ & & $-0.035^{*}$ & $-0.044 \dagger$ \\
\hline & & $(0.03)$ & $(0.05)$ & & $(0.02)$ & $(0.03)$ \\
\hline Log likelihood & -1308.69 & -1284.82 & -420.79 & -1422.28 & -1418.38 & -506.94 \\
\hline $\mathrm{N}$ & 3804 & 3804 & 1494 & 9054 & 9054 & 2761 \\
\hline
\end{tabular}

Note. Standard errors are in parentheses: $\uparrow \mathrm{p}<.10, * \mathrm{p}<.05, * * \mathrm{p}<.01, * * * \mathrm{p}<.001$.

\section{Discussion and Conclusion}

This study was prompted by concerns about when and why, contrary to the predictions of the network embeddedness approach, firms do not prefer relationally or structurally embedded others as their alliance partners. Analysis of code-share alliances in the global airline industry reveals a significant sensitivity to the characteristics of choice sets determined by relational and structural embeddedness. Firms are less likely to choose an option as an alliance partner when there are too few or too many options and when the variation in option embeddedness is low. Analysis results also show that options are less likely to be chosen as alliance partners if there are many alternatives with a greater or equal degree of embeddedness.

The findings of this study may challenge prior research on relational and structural embeddedness. Whereas prior studies have considered relational and structural embeddedness to be determinants of network dynamics (Greve et al., 2010; McFadyen et al., 2009), this study redefined the roles of relational and structural embeddedness as drivers of choice sets with multiple options and showed that alliance formation is significantly affected by the characteristics of choice sets. This investigation therefore added the notion of choice sets to the previous network embeddedness approach and found a significant impact on network dynamics. 
This study also contributes explanations of alliance dynamics. Previous studies of alliance dynamics have examined various mechanisms, including homophily, legitimacy, power and control, and complementarity and compatibility between two potential partners (Hallen, 2008; Mitsuhashi \& Greve, 2009; Rothaermel \& Boeker, 2008). However, these studies tend to limit their analytical focus to actor-to-actor relationships (i.e., relationships between a focal firm and a single potential partner) and ignore the contexts in which potential partners are embedded. This study considers the context of multiple potential partners and demonstrates significant negative effects of attention to multiple options on alliance formation.

Third, this study supports and extends prior studies on choice sets in alliance decisions. Indeed, a few previous studies have recognized the presence of choice sets in partner selection for alliances (Li \& Rowley, 2002). For example, Jensen and Roy (2008) suggested that the market status of a firm shapes that firm's partner choice set and that a firm's reputation operates as the mechanism for partner choice. This study suggested another type of partner choice set based on a network embeddedness approach and verified its effects on alliance decisions.

In addition to its theoretical implications, this study offers managerial implications. Managers can reduce the risks of dissatisfaction with alliance decisions by considering a few reliable options among prior partners or those indirectly connected to others rather than by searching for many options. Ironically, if managers consider many options when seeking to choose the optimal partner for an alliance, this can increase their uncertainty in finding satisfactory partners and undermine decision making in relation to partner selection.

This study has a number of limitations. For example, although the study provides an answer to the question of why two embedded firms do not prefer each other as alliance partners, it is still unable to answer the question of how firms respond to a choice set in alliance decisions because I used the single theoretical approach of network embeddedness. Future work would benefit from other ways of conceptualizing choice sets to reveal further complex mechanisms involved in partner selection. In addition, a shortcoming of my approach is that it explicitly ignores managerial attributes, although such attributes may affect managerial attention and influence strategic decisions. In future research on available data, consideration of the moderating roles of managerial attributes may complement the analyses.

Regardless of these limitations, this study introduces a new mechanism for alliance dynamics based on a choice set determined by network embeddedness, and it provides substantial implications for future work. I hope that the findings of this study provide a theoretical and analytical development in the study of organizational networking behaviors based on partner choice sets.

\section{Acknowledgments}

This study is partly derived from the author's doctoral thesis. The author wishes to thank her supervisor, Prof. Hitoshi Mitsuhashi, for his comments. This work was supported by JSPS Grant-in-Aid for Young Scientists-KAKENHI.

\section{References}

Argote, L., \& Greve, H. R. (2007). A behavioral theory of the firm-40 years and counting: Introduction and impact. Organization Science, 18, 337-349. http://dx.doi.org/10.1287/orsc.1070.0280

Baum, J. A. C., Rowley, T., Shipilov, A. V., \& Chuang, Y. T. (2005). Dancing with strangers: Aspiration performance and the search for underwriting syndicate partners. Administrative Science Quarterly, 50, 536-575. http://dx.doi.org/10.2189/asqu.50.4.536

Bazerman, M. H., Loewenstein, G. F., \& White, S. B. (1992). Reversals of preference in allocation decisions: Judging an alternative versus choosing among alternatives. Administrative Science Quarterly, 37, 220-240. http://dx.doi.org/10.2307/2393222

Besley, D. A., Kuh, E., \& Welsch, R. E. (1980). Regression Diagnostics: Identifying Influential Data and Sources of Collinearity. New York: John Wiley \& Sons.

Borgatti, S. P., \& Foster, P. C. (2003). The network paradigm in organizational research: A review and typology. Journal of Management, 29, 991-1013. http://dx.doi.org/10.1016/S0149-2063_03_00087-4

Burt, R. S. (2002). Bridge decay. Social Networks, 24, 333-363. http://dx.doi.org/10.1016/S0378-8733(02)00017-5

Capaldo, A. (2007). Network structure and innovation: The leveraging of a dual network as a distinctive relational capability. Strategic Management Journal, 28, 585-608. http://dx.doi.org/10.1002/smj.621

Greve, H. R., Mitsuhashi, H., \& Baum, J. A. C. (2013). Greener pastures: Outside options and strategic alliance 
withdrawal. Organization Science, 24, 79-98. http://dx.doi.org/10.1287/orsc.1110.0733

Gulati, R. (1998). Alliances and networks. Strategic Management Journal, 19, 293-319. http://dx.doi.org/10.1002/(SICI)1097-0266(199804)19:4<293::AID-SMJ982>3.0.CO;2-M

Hallen, B. L. (2008). The causes and consequences of the Initial network positions of new organizations: From whom do entrepreneurs receive investments? Administrative Science Quarterly, 53, 685-718. http://dx.doi.org/10.2189/asqu.53.4.685

Hoffman, A. J., \& Ocasio, W. (2001). Not all events are attended equally: Toward a middle-range theory of industry attention to external events. Organization Science, 12, 414-434. http://dx.doi.org/10.1287/orsc.12.4.414.10639

Jensen, M., \& Roy. A. (2008). Staging exchange partner choices: When do status and reputation matter? Academy of Management Journal, 51, 495-516. http://dx.doi.org/10.5465/AMJ.2008.32625985

Larrick, R. P. (1993). Motivatioanl factors in decisions theories: The role of self-protection. Psychological Bulletin, 113, 440-450. http://dx.doi.org/10.1037/0033-2909.113.3.440

Lazzarini, S. G. (2007). The impact of membership in competing alliance constellations: Evidence on the operational performance of global airlines. Strategic Management Journal, 28, 345-367. http://dx.doi.org/10.1002/smj.587

Li, S. X., \& Rowley, T. J. (2002). Inertia and evaluation mechanisms in interorganizational partner selection: Syndicate formation among US investment banks. Academy of Management Journal, 45, 1104-1119. http://dx.doi.org/10.2307/3069427

Maheswaran, D., \& Meyerslevy, J. (1990). The influence of meassage framing and issue involvement. Journal of Marketing Research, 27, 361-367. http://dx.doi.org/10.2307/3172593

Maroun, J. (1991). Decision making in business. New York: Oxford University Press.

McFadyen, M. A., Semadeni, M., \& Cannella, J. A. A. (2009). Value of strong ties to disconnected others: Examining knowledge creation in biomedicine. Organization Science, 20, 552-564. http://dx.doi.org/10.1287/orsc.1080.0388

Mitsuhashi, H. (2012). Almost identical experience biases in vicarious learning. Industrial and Corporate Change, 21, 837-869. http://dx.doi.org/10.1093/icc/dtr068

Mitsuhashi, H., \& Greve, H. R. (2009). A matching theory of alliance formation and organizational success: Complementarity and compatibility. Academy of Management Journal, 52, 975-995. http://dx.doi.org/10.5465/AMJ.2009.44634482

Moran, P. (2005). Structural vs. relational embeddedness: Social capital and managerial performance. Strategic Management Journal, 26, 1129-1151. http://dx.doi.org/10.1002/smj.486

Ocasio, W. (1997). Towards and attention-based view of the firm. Strategic Management Journal, 18, 187-206. http://dx.doi.org/10.1002/(SICI)1097-0266(199707)18:1+<187::AID-SMJ936>3.0.CO;2-K

Rogan, M., \& Sorenson, O. (2014). Picking a (poor) partner: A relational perspective on acquisitions. Administrative Science Quarterly, 59, 301-329. http://dx.doi.org/10.1177/0001839214531719

Rothaermel, F. T., \& Boeker, W. (2008). Old technology meets new technology: Complementarities, similarities, and alliance formation. Strategic Management Journal, 29, 47-77. http://dx.doi.org/10.1002/smj.634

Rowley, T., Behrens, D., \& Krackhardt, D. (2000). Redundant governance structures: An analysis of structural and relational embeddedness in the steel and semiconductor industries. Strategic Management Journal, 21, 369-386. http://dx.doi.org/10.1002/(SICI)1097-0266(200003)21:3<369::AID-SMJ93>3.0.CO;2-M

Schwartz, B. (2004). The paradox of choice: Why less is more. New York: Ecco.

Shipilov, A. V., Rowley, T. J., \& Aharonson, B. S. (2006). When do networks matter? A study of tie formation and decay. Advances in Strategic Management, 23, 481-519.

Skowronski, J. J., \& Carlston, D. E. (1987). Social judgement and social memory: The role of cue diagnosticity in negativity, positivity, and extremity biases. Journal of Personality and Social Psychology, 52, 689-699. http://dx.doi.org/10.1037/0022-3514.52.4.689

Tsai, W., \& Ghoshal, S. (1998). Social capital and value creation: The role of intrafirm networks. Academy of Management Journal, 41, 464-476. http://dx.doi.org/10.2307/257085 
Uzzi, B. (1996). The sources and consequences of embeddedness for the economic performance of organizations: the network effect. American Sociological Review, 61, 674-698. http://dx.doi.org/10.2307/2096399

\section{Copyrights}

Copyright for this article is retained by the author(s), with first publication rights granted to the journal.

This is an open-access article distributed under the terms and conditions of the Creative Commons Attribution license (http://creativecommons.org/licenses/by/3.0/). 